\title{
LOS ENTRESIJOS ACADÉMICOS DE UN EPISODIO HEROICO: REFORMA, INTERVENCIÓN E IMPERIO
}

\author{
Erika Pani \\ El Colegio de México
} $R_{\text {Plural... las revistas culturales iberoamericanas fueron, a }}^{\text {evista de Occidente, }}$ menudo, respuestas creativas a coyunturas críticas. Estudiarlas revela solidaridades imaginadas y redes de colaboración; aspiraciones colectivas por descubrir, difundir o transformar, desde el lenguaje hasta la realidad social y política. Son testigos materiales de aventuras intelectuales, instrumentos para construir la cultura y el futuro. ${ }^{1}$ En cambio, acercarse a las publicaciones disciplinares es, a primera vista, menos emocionante: encorsetadas por la jerga, estructuras y protocolos académicos, lastradas por unos aparatos críticos largos y densos, estas revistas apuestan a la acumulación más que al destello. Es como estudiar, por un lado, una supernova, por el otro, el proceso de sedimentación.

Sin embargo, las revistas académicas son un mirador privilegiado sobre una disciplina. Nos permiten trazar mapas topográficos detallados y confiables de la producción dentro

\footnotetext{
${ }^{1}$ Aimer Granados (coord.), Las revistas en la bistoria intelectual de América Latina: redes, política y cultura, México, Universidad Autónoma Metropolitana, 2012.
} 
de una disciplina precisamente por sus características más prosaicas: su regularidad y permanencia, la sistematización de sus lineamientos, filtros y procesos, y por dirigirse a un público lector que prácticamente espejea a los autores de los textos que en ellas aparecen. Estas publicaciones nos proporcionan los elementos para rastrear la evolución de una disciplina, analizar sus debates y ponderar el peso de problemáticas y perspectivas. Por eso, el 70 aniversario de Historia Mexicana es una invitación tentadora a reflexionar sobre las formas en que se ha escrito la historia mexicanista desde la academia, durante las décadas en que se convirtió en disciplina académica, se profesionalizó, consolidó y desarrolló y hasta la segunda década del siglo xxI.

El denso y violento periodo de la Reforma y la Intervención francesa (1855-1867) es considerado crucial, tanto dentro de la historia que llamamos "patria" como en la académica. Quienes emergieron victoriosos del conflicto no dudaron en describir su gesta como una "segunda guerra de independencia". Miguel Galindo y Galindo consagró a estos años como "la gran década nacional”. El nombre y el rostro de uno de sus más destacados protagonistas, el presidente oaxaqueño Benito Juárez, son, incluso al día de hoy, los más ubicuos dentro del repertorio heroico de la patria. ${ }^{2}$ Con la Independencia y la Revolución, el triunfo de la República sobre el clero, el Imperio y los franceses se ha celebrado -quizá con un aparato festivo más recatado y menos claridad conceptual-como uno de los tres hitos que han definido el devenir de la nación.

Los profesionales de la historia coinciden: durante la época de la Reforma, afirmó Daniel Cosío Villegas, se “consumó la obra

${ }^{2}$ Charles Weeks, The Juarez Myth in Mexico, Tuscaloosa, University of Alabama Press, 1987; Rebeca Villalobos, El culto a Juárez. La construcción retórica del héroe (1872-1976), Ciudad de México, Grano de Sal, Universidad Nacional Autónoma de México, 2020. Puede decirse incluso que el Benemérito se ha vuelto más ubicuo, al ocupar el centro del logotipo del gobierno y haber desplazado a Frida y a Diego del billete de 500 pesos. 
de Hidalgo" y México se constituyó como un país "políticamente moderno". 3 Luis González y González la llamó el "tiempo eje” en la historia del país. La trascendencia de la Reforma, ¿se refleja en las páginas de Historia Mexicana? ¿Qué coyunturas, personajes y procesos, dentro de un periodo abigarrado y movedizo, se consideró debían ser investigados e interpretados desde una perspectiva académica? Para responder a estas preguntas, este texto revisa la manera en que, en la revista, se escudriñaron los años que van del triunfo de la revolución de Ayutla (1855) a la derrota del Imperio (1867), las formas en que los historiadores profesionales entendieron y explicaron el liberalismo reformista, la Guerra de Tres Años, la Intervención francesa y el imperio de Maximiliano.

\section{LA REFORMA: OBJETO DE ATENCIÓN FLUCTUANTE}

Los especialistas del siglo XIX concuerdan en la importancia vital del periodo de la Reforma. Sin embargo, las tensiones, enfrentamientos y transformaciones que lo marcaron no han sido explorados de manera sistemática y sostenida en Historia Mexicana. Las estadísticas recopiladas en las consultas de la versión digital de la revista sugieren que con los lectores sucede algo parecido: entienden que se trata de un periodo importante, cuyas características básicas deben conocer, aunque no les parecen particularmente interesantes. Durante los poco más de cinco años y medio para los que disponemos del número de visitas y descargas de los textos de Historia Mexicana (2015-2020), el resumen más consultado fue el de un artículo sobre la Reforma: el que publicó en 2006 Moisés González Navarro sobre la Ley Juárez, visitado 36143 veces. No obstante, los internautas no accedieron al texto completo sino en 2187 ocasiones (alrededor de $6 \%$ de los que accedieron a la síntesis del texto). En cambio, el

3 Cosío Villegas, “Llamada” (15), 1955, p. 318. 
texto cuyo resumen es el segundo más visto (22 721 veces), que analiza la comercialización del petróleo entre México y Estados Unidos a partir de la década de 1940, ha sido abierto, en su versión completa, 41880 veces (poco más de 184\% del número de veces en que se consultó la versión abreviada). ${ }^{4}$

En la revista han aparecido alrededor de 70 artículos sobre la Reforma, la Intervención y el Imperio; en promedio uno al año. No obstante, como ilustra la gráfica 1, los sucesos y procesos que marcaron estos años turbulentos interesaron a los investigadores de manera intermitente, acicalados, a menudo, por el imperativo de la conmemoración. Empero, no todos los aniversarios merecieron un lugar en el programa editorial de Historia Mexicana. En la década de 1950, ni las leyes reformistas del gobierno de Ayutla, ni el congreso que dominaran aquellos hombres que, según Luis González, “parecían gigantes”, ni el estallido de la Guerra de Reforma, ni la legislación radical de 1859-1860 se discutieron en Historia Mexicana, con todo y que cumplían 100 años.

En cambio, durante la década siguiente, en que más proliferaron los textos sobre el periodo que nos ocupa: 20 artículos, siete testimonios de época y más una docena de reseñas, prueba éstas últimas del entusiasmo editorial que despertó el centenario de

\footnotetext{
4 Avella Alaminos y Hernández Romero, “La comercialización” (268), 2018, pp. 1725-1778. Las estadísticas de la revista están en https://historiamexicana.colmex.mx/index.php/RHM/statistics. La información que ofrecen estos números sorprendentes es fascinante, pero no me queda claro, todavía, cómo debemos leerla. Suponemos que es, todavía, poco representativa por tratarse de los primeros años de acceso y compilación. Con todo, los resultados de las búsquedas son muy sugerentes. Entre 2015 y 2020, entre los tres resúmenes más consultados al año estuvieron tres artículos sobre la Reforma, interpretada en sentido amplio: el de González Navarro (que está en primer lugar en 2020 y 2019, en tercer lugar en 2018), un artículo de Pablo Mijangos sobre las facultades jurisdiccionales de la Iglesia durante las primeras décadas de vida independiente (en segundo lugar en 2016) y un texto de Luis Alberto Arrioja sobre las tierras de los pueblos y la Ley Lerdo (en segundo lugar en 2015).
} 
la Intervención francesa. Desde finales de los cincuenta aparecieron y se reseñaron importantes colecciones documentales: algunos de los papeles de Matías Romero, los del menos prolífico diplomático monarquista José Manuel Hidalgo y los informes diplomáticos franceses que compiló Lilia Díaz. ${ }^{5}$ Se publicaron también análisis críticos de obras señeras sobre el periodo, notables por su originalidad y volumen, aunque no siempre por su calidad. ${ }^{6}$

Por otra parte, para conmemorar la batalla del 5 de mayo de 1862, Historia Mexicana publicó, en su número 44, un dossier que contenía cuatro artículos y cinco documentos de época, competentemente editados y presentados. Los textos de investigación incluyen un artículo sobre las fortificaciones de Puebla y otros dos sobre historia diplomática, uno sobre la deslucida misión del agente confederado en México, otro sobre la -efectiva y trascendente- postura asumida por el gobierno de Juárez ante el escenario internacional tras la caída del imperio. La nota de color la daba, quizá, un texto sobre un personaje simpático, poco conocido y que era, además, mujer: Pepita Peña, que se casó con el jefe del Ejército expedicionario.?

\footnotetext{
5 Monroy, "El archivo” (30), 1958, pp. 208-221; Cosío Villegas, "El diario" (31), 1959, pp. 407-423; ItURRIbarRía, "El diario” (43), 1962, pp. 382-415; Bernstein, "El secreto" (41), 1961, pp. 119-123; "Sobre Guadalupe” (61), 1966, pp. 86-88.

${ }^{6}$ El Primer Congreso Nacional de Historia para el Estudio de la Guerra de Intervención produjo una "copiosa [...] cosecha" de 28 volúmenes que, en opinión del reseñista, "de ningún modo [justificaba] el optimismo" de los editores que creían haber dado "impulso a la investigación histórica", por lo desigual de la colección y la falta de seriedad de muchos de los textos. MoreNo, "Colección" (52), 1964, pp. 627-628. En cambio, el libro de Jack Autrey Dabbs sobre el Ejército expedicionario sigue siendo de lo mejor que hay sobre el tema. Sánchez Lamego, "Jack Autrey" (53), 1964, pp. 157-159.

7 Sánchez Lamego, "Fortificación” (44), 1962, pp. 519-526; Cosío VilleGas, "La doctrina” (44), 1962, pp. 527-545; Fuentes Mares, "La misión” (44), 1962, pp. 487-518; Miquel i Vergés, “Pepita Peña” (44), 1962, pp. 544-573.
} 
ARTÍCULOS, RESEÑAS Y DOCUMENTOS SOBRE LA REFORMA, LA INTERVENCIÓN Y EL IMPERIO 1951-2020

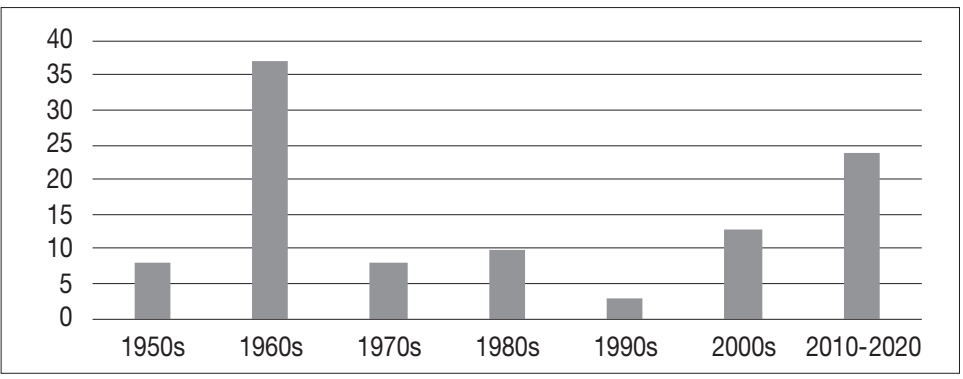

En cada una de las décadas subsiguientes, los artículos sobre el periodo 1855-1867 no rebasaron la decena. En 1972 se publican, "en el centenario de la muerte de Benito Juárez”, seis artículos sobre la era del Benemérito, entre los cuales sólo uno se centra en la figura del presidente oaxaqueño. La discusión de Juárez como "sustancia y esencia incuestionable del principio de autoridad” es, sorprendentemente, la única contribución del prolífico historiador José C. Valadés a la revista. ${ }^{8}$ En la primera década del siglo xxi parece haber un repunte en el interés por los temas de la Reforma que resulta, sin embargo, engañoso. ${ }^{9}$ A lo largo de los 11 años siguientes, hay un aumento sustancial

8 Valadés, “Derivativos” (84), 1972, pp. 557-571; Tamayo, “El Tratado” (84), 1972, pp. 573-613; FrASER, “La política de desamortización” (84), 1972, pp. 615-652; Powell, “Los liberales” (84), 1972, pp. 657-676; GonZÁLEZ Navarro, “La venganza” (84), 1972, pp. 677-692; Keremitsis, "La industria” (84), 1972, pp. 693-724; el número incluye una reseña sobre un estudio de la diplomacia del Segundo Imperio. Ramos, "Sobre Arnold” (84), 1972, pp. 725-727. 9 Se debe esencialmente al aumento en el número de reseñas: seis, de las cuales tres versan sobre el mismo libro, Juárez, que recopila textos publicados por Moisés González Navarro entre 1948 y 2005. Olivares Talavera, "Sobre Moisés” (228), 2008, pp. 1240-1244; VoGT, “Sobre Moisés” (228), 2008, pp. 1244-1246; Covo, “Sobre Moisés” (227), 2008, pp. 975-977. 
en los textos sobre el periodo. De los 18 artículos que tocan el periodo, 9 forman parte de dossiers: el que se publica para marcar el 150 aniversario del Segundo Imperio y otro abocado a la desamortización civil, proceso que rebasa ampliamente a la "gran década nacional", pero para el que la Reforma es una referencia inevitable. Así, más allá de un interés disparejo por marcar ciertos aniversarios, parece haber sido el interés de los investigadores lo que marcó el ritmo de publicación de textos sobre la Reforma.

\section{LA TAREA DEL HISTORIADOR: EPISODIOS}

En el marco del 25 aniversario de Historia Mexicana, Martín Quirarte, Ernesto de la Torre Villar y Arturo Gómez Camacho reflexionaron sobre los logros y pendientes de la historiografía mexicana, el primero sobre la historia política del siglo XIX mexicano, los otros dos sobre la de la Intervención francesa. Se mostraron optimistas: celebraban la consolidación de un mundo editorial dinámico, entusiasmado por la historia e interesado en reeditar "libros fundamentales", fuentes primarias, útiles diccionarios, textos escolares y obras de síntesis. Se discutía de historia acalorada pero ecuánimemente en la prensa, y además circulaban revistas especializadas empeñadas en "exponer el pasado de la manera más objetiva posible [...y] lograr la mayor ponderación crítica”. El tiempo por venir prometía ser bueno para la historiografía. ${ }^{10}$

El dictamen que pronunciaron estos historiadores sobre la historiografía de la Reforma es equilibrado y se ajusta a su vocación académica y al momento historiográfico. Encomiaron lo que se había hecho: los lectores podían aprender mucho de la gesta militar y de la extraordinaria vida de Juárez; habían aparecido textos que ofrecían visiones equilibradas, que exponían

10 Quirarte, “Historia política” (58-59), 1965-1966, pp. 412-413. 
los puntos de vista mexicano y ultramarino, conservador y liberal. ${ }^{11}$ Apuntaron que hacía falta, sin embargo, ocuparse de los numerosos personajes históricos, de ambos bandos, que hasta entonces habían sido opacados por el Benemérito. Del Villar y Gómez Camacho insistieron en la necesidad de actualizar las miradas sobre la Intervención, desentrañando sus "aspectos socio-económicos", indagando sobre el lugar que ocupaba dentro de la expansión capitalista global. Por su parte, Quirarte apuntó que la Reforma había recibido más atención que la Intervención y que los estudios sobre el Imperio eran casi inexistentes, quizá por temor de los estudiosos a que se les endilgara "el calificativo de imperialistas o conservadores". ${ }^{12}$ El historiador tapatío hacía votos por que quienes solventaran estas carencias fueran historiadores mexicanos. ${ }^{13}$

En 1976, Josefina Z. Vázquez sentó a Historia Mexicana "en el banquillo" al llegar la revista al número 100. La autora reparó también en la respetable cantidad de autores extranjeros dedicados a hurgar en el pasado mexicano, pero lo consideró muestra de un provechoso "creciente interés mexicanista en el exterior". ${ }^{14} \mathrm{Su}$ análisis muestra que se justificaba la confianza de quienes la habían precedido en el corte de caja historiográfico, particularmente en lo que se refería al siglo XIX. Lejos de representar, como alegaron algunos de sus estudiosos, unos "años perdidos y olvidados", ${ }^{15} \mathrm{el}$ siglo de la independencia $-y$, particularmente la segunda mitadhabía sido el más trabajado por los autores de la revista.

11 De la Torre y Gómez Camacho, “La Intervención” (60), 1966, pp. 580624, esp. p. 582.

12 De la Torre y Gómez Camacho, “La Intervención” (60), 1966, pp. 580-624, esp. p. 584.

13 Quirarte, “Historia” (58-59), 1965-1966, pp. 408-424, esp. p. 411.

14 VÁzquez, “Historia Mexicana en el banquillo” (100), 1976, pp. 642-654. Posteriormente, en el cuarenta aniversario de la revista, "Historia Mexicana en el banquillo" (161), 1991, pp. 11-24, esp. p. 16.

15 Walther L. Bernecker, "México en el siglo XIX: ¿años olvidados y perdidos?”, en Iberoamericana, 3: 9 (2003), pp. 209-220. 
Los textos publicados por una Historia Mexicana más madura e institucional exhibían las posibilidades de explorar el tradicional relato decimonónico con novedosas herramientas teórico-metodológicas. Buen ejemplo de ello es el número conmemorativo del centenario de la muerte de Juárez, centrado en temas de la historia económica y social, y no en el puñado de hombres tiesos que, guerreando y legislando, nos habían dado patria. ${ }^{16}$ La historia política, sin embargo, dominó -con más de la mitad de los artículos- los estudios sobre el siglo XIX aparecidos, durante 50 años, en Historia Mexicana. ${ }^{17}$

En los 30 años que siguieron, se confirmaron, para el periodo 1855-1867, las tendencias que apuntara Vázquez para el siglo XIX. Poco más de la mitad de los artículos publicados $-55 \%$ - tratan temas que pueden clasificarse como políticos, lo que es quizá inevitable dada la naturaleza de la coyuntura. Sin embargo, los investigadores recurren a perspectivas cada vez más eclécticas para mirar el poder y las maneras en que se construye, norma, ejerce, interpela o desafía: “desde abajo”, ${ }^{18}$ por medio del derecho y la cultura, ${ }^{19}$ o desde una perspectiva transnacional. ${ }^{20}$ Así, aunque se prolongó el predominio de la historia

16 Véase la nota 8. Compárese, por ejemplo, con el repertorio, más tradicional, del volumen conmemorativo de la batalla de Puebla.

17 VÁzquez, “Historia Mexicana en el banquillo” (161) (jul-sep. 1991), pp. 11-24, esp. pp. 21-22.

18 FAlcón, “Descontento” (175), 1995, pp. 461-498; Marino, “Ahora que Dios” (220), 2006, pp. 1353-1410; SÁnchEZ, “Los proyectos” (250), 2013, pp. 689-743; LiRa Larios, “De buenos mexicanos” (275), 2020, pp. 1091-1142.

19 González Navarro, “La Ley Juárez” (219), 2006, pp. 947-972; MijanGos, “Entre la igualdad” (261), 2016, pp. 7-64; López GonzÁlez, “Cultura jurídica” (220), 2016, pp. 1289-1351; PANTOJA Morán, “La Constitución” (228), 2008, pp. 1045-1106; BeEzley, “Cómo fue” (226), 2007, pp. 405-444; PANI, "El proyecto” (178), 1995, pp. 423-460; CoudART, "La regulación” (258), 2015, pp. 629-687; De la Torre Hernández, “El bestiario” (258), 2015, pp. 689-718.

20 Cárdenas Ayala, “El fin de una era” (258), 2015, pp. 719-746; Garner, “El 'Imperio”” (258), 2015, pp. 541-559; Buriano, “Entre” (258), 2015, pp. 
política que había inquietado a los investigadores en 1966, puede decirse que ésta se volvió más abarcadora, incluso más sofisticada.

Por otra parte, se hicieron realidad muchos de los deseos enunciados al cumplir la revista 25 años. Poco más de 30\% de los artículos publicados entre 1991 y 2020 versan sobre historia económica e incluyen un par de textos sobre los intereses materiales que incentivaron la Intervención. ${ }^{21}$ La mayoría de los textos (cinco) se ocupa de la desamortización como proceso económico y social. ${ }^{22}$ En cambio, la historia militar, tan apreciada por los historiadores "tradicionales", figura muy poco. La de viejo cuño hace un par de apariciones obligadas, producto, en su mayoría, de la pluma de oficiales historiadores. La "nueva" historia militar está casi totalmente ausente, a pesar de la importancia determinante de la violencia durante los años que nos interesan. ${ }^{23}$

561-597; Crespo, “La tentación” (258), 2015, pp. 599-628; SweEney, “Sobre su cadáver” (272), 2019, pp. 1639-1696. En cuanto a la relevancia del entorno internacional para los estudios de la Intervención en las páginas de Historia Mexicana, prácticamente desde su fundación, véanse McCoRnACK, "Los Estados” (15), 1955, pp. 337-352; Dougherty, “Gran Bretaña” (55), 1965, pp. 383-415; Caillet-Bois, “Argentina” (48), 1963, pp. 552-594; López Chirico, “La Intervención” (74), 1969, pp. 248-281; Fuentes Mares, "La misión” (44), 1962, pp. 487-518; "Washington” (50), 1963, pp. 244-271.

21 Moreno, "Christian Schefer” (49), 1963, pp. 107-109; Helguera, "Posibles antecedentes” (57), 1965, pp. 1-24.

22 Sobre desamortización, Arrioja, "Pueblos” (254), 2014, pp. 487-532; KouRI, "Sobre la propiedad comunal” (264), 2017, pp. 1923-1960; MEndoza GaRCíA, “Tierras” (264), 2017, pp. 1961-2011; PÉrez Montesinos, “Geografía” (264), 2017, pp. 2073-2149. Ya en 1966, Jan Bazant había explorado las “consecuencias sociales y económicas" de la desamortización de bienes corporativos de 1856, siendo los bienes pertenecientes a los conventos los que "formaban el grueso de los bienes corporativos". BAzANT, "La desamortización” (62), 1966, pp. 193-212. Sobre guerra y comercio, CERUtTi y González Quiroga, "Guerra y comercio" (158), 1990, pp. 217-297; sobre banca, LudLOw, "La disputa” (188), 1998, pp. 765-805; sobre el petróleo, Riguzzi y GERALI, “Los veneros" (258), 2015, pp. 747-808.

23 Sánchez Lamego, “Fortificación” (44), 1962, pp. 519-526 y “El combate de Atlixco” (62), 1966, pp. 184-192; Penette y Castaingt, “La Legión” (46), 
De manera similar, el Benemérito de las Américas no acapara reflectores en Historia Mexicana. Apenas se discute, en sus páginas, parte de su obra portentosa: el tratado por el que ha sido denostado, la ley que reformó y organizó la administración de la justicia federal en 1855 y la doctrina de política exterior con la que México había “dado una nueva mano en el juego de cartas internacional” tras la caída del Imperio. ${ }^{24}$ De hecho-¿̇manifestación quizá de las aspiraciones científicas de los académicos?-, la dimensión personal-trágica, corrupta o heroica- está casi ausente de la revista, salvo los esbozos de ciertas personalidades llamativas: Pickett, Maximiliano, el abate arqueólogo Charles Étienne Brasseur de Bourbourg. ${ }^{25}$ Con todo, Ignacio Comonfort, el presidente moderado y golpista, que ocupa un lugar ambivalente en la crónica liberal, es el protagonista de tres artículos y una polémica. El prodigioso Matías Romero aparece en dos, por republicano, joven y amiguero. ${ }^{26}$

1962, pp. 229-273; más novedoso resulta TAYlor Hansen, "Voluntarios" (146), 1987, pp. 205-237. El general Sánchez Lamego editaría también dos documentos sobre los enfrentamientos armados de la era de la Reforma: "Un episodio” (52), 1964, pp. 600-615 y “El combate de Barranca Seca” (55), 1965, pp. 469-487, y una reseña del libro de J. A. Dabbs the French Army in Mexico: "Jack Autrey" (53), 1964, pp. 157-159. El general Daniel Gutiérrez Santos editó los testimonios sobre la batalla del 5 de mayo publicados en el núm. 44: Gutiérrez SANTOs, “El cinco” (44), 1962, pp. 579-602, y Marcel Penette era también antiguo oficial. Mario Cerutti y Miguel Ángel González Quiroga, por su parte, publican un artículo notable sobre el dinamismo económico del espacio fronterizo durante la guerra, estimulado, "justamente, por imperativos bélicos”. "Guerra”, p. 217.

24 Tamayo, "El Tratado” (84), 1972, pp. 573-613; González Navarro, “La Ley Juárez” (219), 2006, pp. 947-972; Cosío Villegas, “La doctrina” (44), 1962 , p. 529.

25 Fuentes Mares, “La misión” (44), 1962, pp. 487-518; Sten, “Brasseur” (105), 1977, pp. 141-148.

26 Broussard, “Mocedades” (51), 1964, pp. 379-393 y “El regreso” (64), 1967, pp. 516-530; Hernández Rodríguez, “Comonfort” (49), 1963, pp. 59-75 y "Sobre Ray F. Broussard” (76), 1970, pp. 587-589; Bernstein, “Mocedades” (40), 1961, pp. 588-612; Donoso, “Una amistad” (22), 195, pp. 294-320. 
Los estudiosos que sondearon el panorama historiográfico en 1966 repararon en la falta de trabajos sobre el Segundo Imperio. Hasta la década de 1990 se confirmó esta ausencia: Historia Mexicana publicó, en promedio, poco más de un artículo sobre el Imperio, o sobre lo que se había dicho del Imperio, cada diez años. ${ }^{27}$ El número aumenta, de manera sustancial, a partir de la década de 1990, cuando el Imperio se convierte en un tema recurrente, analizado desde una diversidad de puntos de vista: los proyectos políticos y económicos del gobierno imperial, la opinión pública, las reverberaciones del régimen allende las fronteras de México. ${ }^{28}$ Aunque algunos de estos textos se ocupan de las particularidades de la breve restauración monárquica -la construcción de un imaginario monárquico, el indigenismo de Maximiliano, la caricatura antimonarquista-, ${ }^{29}$ la mayoría refleja, con mayor provecho, la normalización de los años que van de 1864 y 1867, examinados para entender procesos que el

Escribe también sobre Romero Cosío Villegas, “La aventura” (29), 1958, pp. 35-59, pero se refiere a sus inversiones e intervenciones en la economía cafetalera en la frontera con Guatemala.

27 Zavala, "Victor Considérant" (27), 1958, pp. 309-328; Fuentes Mares, "Washington” (50), 1963, pp. 244-271; Hernández Luna, "Sobre el Imperio" (66), 1967, pp. 230-239; Sten, "Brasseur” (105), 1977, pp. 141-148; BazanT, "Secuestro" (128), 1983, pp. 554-576; Weckmann, "México" (153), 1989, pp. 235-241.

28 Ludlow, "La disputa" (188), 1998, pp. 765-805; PANI, "El proyecto" (178), 1995, pp. 423-460 y "Verdaderas" (187), 1998, pp. 571-604; MARINo, "Ahora que Dios” (220), 2006, pp. 1353-1410; López González, "Cultura jurídica” (220), 2016, pp. 1289-1351; Trejo, "Estructura” (228), 2008, pp. 1013-1044; SÁnchez, "Los proyectos" (250), 20I3, pp. 689-743; Buriano, "Entre” (258), 2015, pp. 561-597; Cárdenas Ayala, "El fin de una era" (258), 2015, pp. 719-746; Coudart, "La regulación” (258), 2015, pp. 629-687; Crespo, "La tentación” (258), 2015, pp. 599-628; GARNER, “El ‘Imperio”” (258), 2015, pp. 541-559; De la Torre Hernández, "El bestiario" (258), 2015, pp. 689-718; Riguzzi y Gerali, “Los veneros” (258), 2015, pp. 747-808; SweEney, “Sobre su cadáver” (272), 2019, pp. 1639-1696.

29 PANI, “¿"Verdaderas”?” (187), 1998, pp. 571-604; Marino, “Ahora que Dios” (220), 2006, pp. 1353-1410. 
imperio enmarca pero no determina: la construcción del Estado y del sistema financiero, el fomento económico, la prensa.

Si el Imperio -con el empujón que le dio el 150 aniversario-se puso de moda, no se despertó entre quienes publican en Historia Mexicana un interés similar por los conservadores, artífices del experimento monárquico y contendientes en la Guerra de Reforma que lo precedió. Al parecer, el bando derrotado sigue interesando poco. A lo largo de 70 años, apenas cuatro artículos se ocupan del conservadurismo radical que, durante esta época turbulenta, se opuso al liberalismo reformista. ${ }^{30}$

\section{PARA ENTENDER LA REFORMA. LAS HERRAMIENTAS}

\section{DEL HISTORIADOR}

¿Cómo se ponderaron, en las páginas de Historia Mexicana y a lo largo de 70 años, las consecuencias de las rupturas profundas y los complejos procesos de transformación que identificamos con el evocativo pero hermético membrete de La Reforma? ¿Cómo han cambiado las perspectivas, procedimientos y conclusiones de quienes los estudian? Podemos empezar por el tono. Se ha mantenido, como los inalterados forros verdes, una prosa rigurosa y más bien aséptica, reflejo quizá de aspiraciones científicas. Después de un par de décadas desaparecieron incluso los "títulos ingeniosos", pensados para "aligerar la revista", y las réplicas y controversias se han vuelto excepcionales. Nadie escribe ya con la malicia de un José Fuentes Mares, cuyos escritos, alegara Luis González y González, caían a algunos como "patada en las partes nobles", y sorprendería hoy que algún investigador describiera a la autora de una obra reseñada -que

30 Bazant, "La Iglesia” (137), 1985, 93-109; Acle Aguirre, “Amigos” (241), 2011, pp. 163-230; FAlcón, "Descontento" (175), 1995, pp. 461-498; LirA LARIOs, “De buenos mexicanos" (275), 2020, pp. 1091-1142. Estos dos últimos artículos no se centran en el conservadurismo, pero escudriñan sociologías y conflictos que obstaculizaron la consolidación del orden liberal. 
además resultaba ser su parienta- como una "dama culta y de buen gusto". ${ }^{31}$

En cuanto a los temas analizados, también podría alegarse que ha privado la continuidad sobre el cambio. Para entender la Reforma, los historiadores académicos, a diferencia de lo que, podría argüirse, sucedió con la Independencia, no la voltearon de cabeza. Tres temas, principalmente, han articulado los estudios sobre el periodo: el liberalismo y su dimensión revolucionaria, la relación Iglesia-Estado y la "secularización" de la sociedad, y la desamortización, con sus ritmos, mecanismos y consecuencias. Lo que sí ha cambiado, y con ello enriquecido nuestras interpretaciones, son los enfoques con los que los investigadores se han acercado a ellos.

El liberalismo, tema inescapable para quienes se interesan en el siglo xIx mexicano, es visto como motor y lenguaje de las transformaciones del medio siglo. En un principio, los autores tratan de precisar y matizar los objetivos de los liberales mexicanos, más modernizadores -capitalistas y burgueses, por convicción más que por experiencia- que anticlericales, y apuntan los límites de una revolución burguesa atravesada por aspiraciones democráticas. Las tensiones entre liberalismo y democracia vuelven a revisarse, provocadoramente, en la década de 2010, desde la perspectiva de la historia intelectual: mientras que en la década de 1960 se afirma que al crear "una numerosa clase de trabajadores a veces esclavos, otras veces peones-siervos o libres" la Reforma defrauda a la democracia, a finales de 2010 se contrapone su "victoria conceptual arrasadora", a su repliegue como objetivo concreto de la lucha política, al transformarse

${ }^{11}$ VÁzquez, "Historia Mexicana en el banquillo" (161) (jul-sep.1991), p. 15; la semblanza que escribiera González y González del historiador chihuahense está disponible en https://www.acadmexhistoria.org.mx/pdfs/members_previous/res_j_fuentes_mares.pdf; LANCASTER-JONES, “Imperialista” (10), 1961, pp. 663-667, esp. p. 667. 
en una bandera "de vagos contornos [...] devorada por la retórica cívica y patriótica”. ${ }^{32}$

En la década de 1980, en un esfuerzo por justipreciar tanto las realidades sociopolíticas como "la importancia de la dimensión doctrinal”, el liberalismo se convierte en lente más que objeto de estudio. Este enfoque permite revelar el papel del liberalismo como generador de una cultura política que permitía forjar alianzas -sin duda frágiles y contradictorias- de alcance nacional y que daba a las "masas [...] cierta ventaja táctica". Si el discurso liberal movilizó, sus instituciones articularon políticas fiscales centralizadoras que permitieron apuntalar la consolidación del mercado y esbozar la transformación -al final malogradadel gobierno federal en garante efectivo de derechos y promotor del desarrollo. ${ }^{33}$

La secularización se considera el legado más trascendente de la Reforma, resultado de una lucha a muerte entre dos fuerzas antagónicas e "impermeables". Los artículos sobre el tema en Historia Mexicana son menos numerosos que las reseñas sobre el mismo que publica, lo que sugiere que la renovación del debate sobre el conflicto religioso de mediados del siglo XIX se refleja pero no se lleva a cabo en las páginas de la revista. ${ }^{34}$ Lo que se escribe sobre la Iglesia procura, sin embargo, desde la década de los sesenta, mostrar la complejidad de un proceso cuyo desenlace no estaba prescrito ni era inevitable: la Iglesia no era un monolito y su oposición al proyecto liberal -aunque

\footnotetext{
32 Scholes, "El liberalismo" (7), 1953, pp. 343-352; Bazant, "Tres revoluciones" (38), 1960, pp. 220-243, pp. 230-237, p. 236. Aguilar Rivera, "La redención" (273), 2019, pp. 7-56.

33 Knight, "El liberalismo" (137), 1985, pp. 59-91, pp. 63 y 65; Carmagnani, “El liberalismo" (151), 1989, pp. 471-496, pp. 471 y 494.

${ }^{34}$ Éstas se vuelven más numerosas en la década de 2010: Mijangos, "Sobre Marta Eugenia García Ugarte” (242), 2011, pp. 729-736; Carbajal, "Sobre Pablo Mijangos" (260), 2016, pp. 1943-1949; Ceballos, "Juan Carlos Casas García y Pablo Mijangos y González” (265), 2017, pp. 476-480.
} 
“contribuyó significativamente a la década de desastres"- no giraba sólo en torno a la defensa del pasado y de sus intereses. ${ }^{35}$

Siguiendo esta línea, textos más recientes revelan la dimensión estructural, de más larga duración, trasatlántica y moderna del conflicto. Una vez más, el cambiar el enfoque permite precisar, matizar y complejizar, por encima de supuestos y prejuicios, las formas de reaccionar y actuar de ciertos actores. Por un lado se analizan los esfuerzos del obispo de Puebla para negociar la paz en medio de una rebelión azuzada por curas de pueblo. Por el otro, se describen las vivencias de quienes normalmente se consideran sujetos silenciosos y marginales de las leyes reformistas: los miembros de las órdenes religiosas masculinas, ${ }^{36} \mathrm{y}$ se examinan los objetivos políticos y pragmáticos del embate en contra de los fueros, esfuerzo que se finca en la experiencia de los arquitectos del Estado qua Estado, más que en su afán por verlo laico. ${ }^{37}$

Jan Bazant, quizá el más lúcido y ecléctico de los estudiosos de la Reforma en Historia Mexicana, afirmaba, a mediados de los sesenta, que ya se había discutido "detalladamente el contenido jurídico, político e ideológico” de la legislación reformista. En cambio, sus “consecuencias sociales y económicas” habían sido tratadas sólo esquemáticamente, y tenía que ampliarse y profundizarse su investigación. ${ }^{38}$ Los que respondieron a su convocatoria exploraron las manifestaciones concretas de la revolución por medio de los procesos de desamortización ordenados por la Ley Lerdo de junio de 1856, de los bienes eclesiásticos en

35 Knowlton, “La Iglesia mexicana” (72), 1969, pp. 516-534, esp. p. 534.

36 Cárdenas Ayala, "El fin de una era” (258), 2015, pp. 719-746; Bazant, "La Iglesia” (137), 1985, pp. 93-109.

37 Mijangos, “Entre la igualdad” (261), 2016, pp. 7-64, esp. p. 54.

38 BAzANT, “La desamortización” (62), 1966, pp. 193-212, esp. p. 193. Bazant será el reseñista más asiduo de las obras que trataban del periodo de la Reforma: BAzANT, "Sobre Michael P. Costeloe” (70), 1968, pp. 312-314; "Sobre Mario Cerutti” (133), 1984, pp. 168-169; “Sobre Jacqueline Covo” (136), 1985, pp. 734-736; “Sobre Robert J. Knowlton” (104), 1977, pp. 630-632. 
un primer momento, de las tierras de los pueblos después y por más tiempo. De las investigaciones sobre la Reforma publicadas en Historia Mexicana, se trata quizá de la que más frutos ha rendido. La historia de la desamortización parte del sólido pero parco análisis cuantitativo de Bazant y expone, paralelamente, la versión convencional que ve en la ejecución de la Ley Lerdo -que no en su reinterpretación durante el porfiriato- el origen de la miseria campesina y la semilla del agrarismo revolucionario, por haber empobrecido y desmoralizado "a toda una clase social". 39

Empero, casi al mismo tiempo, empiezan a publicarse análisis que estudian la desamortización como un proceso prácticamente secular e insisten en la importancia de la dimensión regional y local. Estos textos exploran las coyunturas y factores que incentivan y moldean los procesos de desamortización: el peso de los intereses locales y de los bienes comunales indígenas en la economía estatal, las heterogéneas formas de propiedad, el acceso al agua, a los circuitos comerciales y a las líneas de ferrocarril. Como es el caso para los estudios sobre la Iglesia, estos textos revelan la gran diversidad de actitudes y estrategias, articuladas por una multitud de protagonistas que dan forma a un proceso prolongado y complicado: "pueblos que quieren y piden subdividir sus terrenos, indígenas desamortizadores, comuneros acomodados que acaparan las tierras de sus condueños, vecinos que prefieren la pequeña propiedad, especuladores y leguleyos que son hijos del pueblo y trafican con sus tierras". ${ }^{40}$

39 Bazant, “Tres revoluciones” (38), 1960, pp. 220-243, esp. pp. 230-237 y p. 236; Powell, “Los liberales” (84), 1972, pp. 653-676; Fraser, "La política de desamortización” (84), 1972, pp. 615-652.

40 Arrioja, "Pueblos” (254), 2014, pp. 487-532, esp. p. 523; Knowlton, “La individualización” (109), 1978, pp. 24-61; “La división de las tierras” (157), 1990, pp. 3-25; “Tribunales” (18), 1996, pp. 71-98; “El ejido” (189), 1998, pp. 71-96; Pérez Montesinos, “Geografía” (264), 2017, pp. 2073-2149; MendoZA GARcíA, “Tierras” (264), 2017, pp. 1961-2011; Kourí, “Sobre la propiedad comunal” (264), 2017, pp. 1923-1960, esp. p. 1924. 
Los estudios sobre la Reforma, entendida en sentido amplio, están presentes, pero no abundan en las páginas de Historia Mexicana. Esto no debe ni sorprender ni preocupar. El periodo se definió -en el siglo XIX- por incentivos esencialmente políticos, y pocos son los historiadores que, justificadamente, aspiran a convertirse en expertos en cinco, diez o doce años del siglo antepasado. Se interesan, en cambio, en entender problemas, coyunturas o procesos, que son los que deben ser analizados en las páginas de la revista. Los historiadores han rodeado el relato patriótico, han echado mano de enfoques y herramientas diversas para indagar en los factores de cambio y continuidad que han determinado las múltiples formas de vivir, pensar, alegar, producir de los mexicanos al mediar el siglo xIx. Como publicación académica, Historia Mexicana ha hecho lo que esperamos que haga una publicación periódica académica, aunque le quedan cosas por hacer. Sobre el conocimiento acumulado, sin desplantes ni florituras, ha profundizado y complicado las maneras en que entendemos las complejas, sangrientas, proteicas décadas de mediados del siglo XIX. 